\title{
Comparative Quantitative Angiographic Analysis of Directional Coronary Atherectomy and Balloon Coronary Angioplasty
}

\author{
Victor A. W. M. Umans, MD, Kevin J. Beatt, MD, Benno J. W. M. Rensing, MD, \\ Walter R. M. Hermans, MD, Pim J. de Feyter, MD, PhD, and Patrick W. Serruys, MD, PhD, \\ with the technical assistance of Eline Montauban van Swijndregt
}

An attempt to assess the "utility" of directional atherectomy was made using a new quantitative angiographic index. This index can be subdivided into an initial gain component and a restenosis component. The initial gain index is the ratio between the gain in diameter during intervention and the theoretically achievable gain (i.e., reference diameter). The restenosis index is the ratio between the decrease at follow-up and the initial gain during the procedure. The net result at long-term follow-up is characterized by the utillIy index, which is the ratio between the final gain in diameter at follow-up and what theoretically could have been achieved. For this purpose, 30 coronary artery lesions were selected from a consecutive series of successfully dilated primary angioplasty lesions and were matched with the initial $\mathbf{3 0}$ successfully treated primary atherectomy lesions. Matching by location of stenosis and reference diameter resulted in $\mathbf{2}$ comparable groups with identical preprocedural stenosis characteristics. Athereclomy resulted in an increase in minimal luminal diameter 2 times larger than angioplasty (1.53 vs $0.77 \mathrm{~mm}$; $<0.0001$ ). However, at follow-up there was a stgnlficant decrease in minimal luminal diameter and a significant increase in percent diameter stenosis in the groups with atherectomy and angioplasty (1.69 \pm 0.58 vs $1.57 \pm 0.58 \mathrm{~mm}$, $p=$ not significant [NS], and $37 \pm 18$ vs $47 \pm$ $18 \%, p=N S$, respectively). The decrease in minimal Iuminal gain was more pronounced in the group with atherectomy than in that with angioplasty $(0.92 \pm 0.69$ vs $0.35 \pm 0.51 \mathrm{~mm}$; $p=0.0005$ ). Consequently, directional atherec-

From the Catheterization Laboratory, Thoraxcenter, University Hospital Dijkzigt, Erasmus University Rotterdam, the Netherlands. This study was supported in part by Grant 89.241 from the Netherlands Heart Foundation, The Hague. Manuscript received May 8, 1991; revised manuscript received and accepted July $25,1991$.

Address for reprints: Patrick W. Serruys, MD, PhD, Catheterization Laboratory, Thoraxcenter, Erasmus University Rotterdam, P.O. Box 1738, 3000 DR Rotterdam, the Netherlands. tomy resulted in a significantly higher initial gain ratio than did balloon angioplasty $(0.84$ vs 0.41 , $p<0.00001$ ). At follow-up, restenosis and utifty ratios were comparable in both groups (0.56 vs $0.62, p=N S$, and 0.29 vs $0.23, p=N S$, respectively). In matched groups, directional atherectomy is a very effective device with a substantially better initial result than that with balloon angioplasty. However, it appears to be a potent stimulator of the restenosis process, because at follow-up this initial favorable result is lost, and the minimal luminal diameter is comparable to that after balloon angioplasty. Thus, the final utility of directional coronary atherectomy is not significantly different from that of conventional balloon angioplasty.

(Am J Cardiol 1991,68:1556-1563)

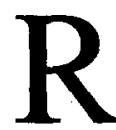
estenosis after conventional balloon angioplasty remains the major limitation of this procedure. $^{1-5}$ Despite extensive efforts to elucidate this phenomenon, our knowledge remains incomplete. In recent years studies have suggested that intimal hyperplasia is the major mechanism responsible for restenosis $^{6-9}$ and that lesion characteristics and regional flow dynamics influence this proliferative process. ${ }^{10}$ Because improved operator cxpcrience and angioplasty techniques have not caused a reduction in restenosis rates, interventional cardiologists have designed new devices aimed at debulking instead of dilating atherosclerotic plaque. Directional atherectomy is a new technique with the potential advantage of creating smooth luminal surface. However, early experience with atherectomy indicates that restenosis rates are comparable with those after conventional balloon angioplasty, although a randomized study has not been initiated. ${ }^{11-13}$ Recently it has been demonstrated that the immediate results of atherectomy are superior to those achieved by balloon angioplasty ${ }^{14}$; whether this initial advantage can be maintained during follow-up and may ultimately result in a reduction of the restenosis rate needs to be 
assessed. Therefore, the present study was performed to determine whether this initial favorable result obtained with atherectomy affects the incidence of restenosis.

\section{METHODS}

Patient group: From September 1989 through January 1991, 66 patients underwent 74 atherectomy procedures. For the purpose of this study, the initial 30 consecutive patients ( 23 men and 7 women, mean age \pm standard deviation $60.2 \pm 10.1$ ) who underwent an angiographically successful procedure (postprocedural diameter stenosis $<50 \%$, with tissue retrieval) of a primary lesion in a native coronary artery were selected. At the time of atherectomy, 16 patients were in New York Heart Association functional class IV, 7 in III and 7 in II. Coronary angiography showed 1-vessel disease in 25 patients, 2-vessel disease in 4 and 3-vessel disease in 1. The site of obstruction was located in the left anterior descending coronary artery in 18 patients, the right coronary artery in 7 and the circumflex artery in 5.

Atherectomy procedure: After administration of lo$\mathrm{cal}$ anesthesia, an 11Fr sheath was inserted in the femoral artery. All patients received $250 \mathrm{mg}$ of acetylsalicylic acid and $10,000 \mathrm{U}$ of heparin intravenously. Intracoronary injection of isosorbide dinitrate was performed to optimally vasodilate the vessel. After initial angiograms in multiple views were obtained, a special $11 \mathrm{Fr}$ guiding catheter was placed into the ostium of the coronary artery. Under fluoroscopy, the guidewire was advanced in the distal part of the artery. Then, the atherectomy device was directed over the guidewire and positioned across the stenosis. The support balloon was then inflated up to $0.5 \mathrm{~atm}$, the cutter was retracted and balloon inflation pressure was increased to 2 to 3 atm. The driving motor was activated, and the rotating cutter was slowly advanced to cut and collect the pro- truding atherosclerotic lesion in the collecting chamber located at the tip of the catheter. After every pass, the balloon was deflated and either removed or repositioned. On average, $6.7 \pm 2.9$ passes in multiple directions were performed across a stenosis. Atherectomy was considered successful when the residual stenosis was $<50 \%$ after tissue retrieval. After atherectomy, the arterial and venous sheaths were usually left in place for 6 hours. Patients were monitored for 24 hours, and electrocardiograms and cardiac enzyme levels were obtained twice daily. Nifedipine was administered every 2 hours for 24 hours after the procedure, and the patients were administered aspirin for 1 year.

Follow-up evaluation: After successful atherectomy or angioplasty (i.e., $<50 \%$ postprocedural diameter stenosis on visual inspection), patients were examined at the outpatient clinic. The follow-up coronary angiogram was obtained within 2 weeks after an exercise test. Angiography was performed earlier if symptoms occurred within 6 months.

Quantitative coronary angiography: Quantitative analysis of the coronary segments was performed with the computer-based Coronary Angiography Analysis System (CAAS), previously described in detail. $4,5,15,16$ In essence, boundaries of a selected coronary artery segment were detected automatically from optically magnified and video-digitized regions of interest (512 $\times 512$ pixels) of a cineframe. The absolute diameter of the stenosis in millimeters was determined using the guiding catheter as a scaling device. Each individual catheter was measured with a micrometer and used as a scaling device. Correction for pincushion distortion was performed. The computer-estimation of the original dimension of the artery at the site of the obstruction was used to define the interpolated reference diameter. The percentage diameter and area stenosis, as well as the cross-sectional area $\left(\mathrm{mm}^{2}\right)$, were then calculated.

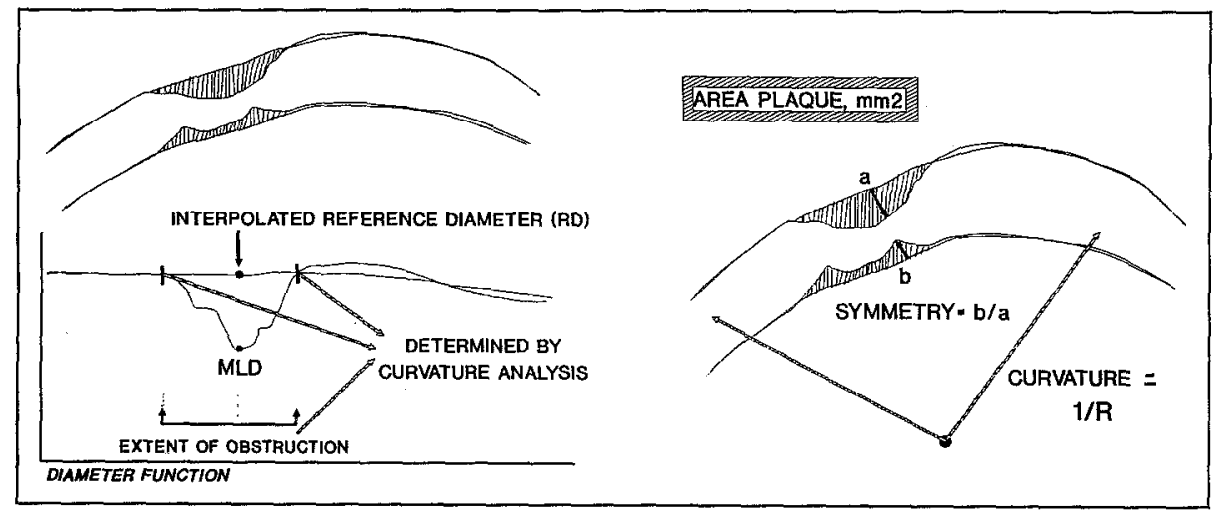

FICURE 1. Graphic illustration of stenosis parameters chtained by quantitative coronary analysis. Left, y axis represents reference diameter, and vessel length is represented along $x$ axis. Reference diameter and lesion length aro detormined by diameter at bounderies of lesion that are defined by curvature analysis. Right, curvature analysis is described. Curvature is defined by rate of change of angle through which tangent of curve turns, and which for a circle is equal to reciprocal of radius (R). MLD = minimal huminal diameter . 
The length of the lesion (mm) was determined from the diameter function on the basis of curvature analysis (Figure 1). Symmetry was defined as the coefficient of the left-hand distance between the reconstructed interpolated reference diameter and actual vessel contours, and the right-hand distance between the reconstructed and actual contours at the site of the obstruction. Symmetry index ranged from 0 (totally eccentric stenosis) to 1 (symmetric). The degree of coronary bend was assessed by the curvature value at the obstruction site. This parameter was computed as the average value of all individual curvature values along the centerline of the coronary segment, with curvature defined as the first derivative of the tangent as it moves along the centerline, which for a circle is equal to the reciprocal of the radius. The area between the actual and reconstructed contours at the obstruction site was defined as the area plaque (expressed in $\mathrm{mm}^{2}$ ). To standardize the method of analysis of the interventional and follow-up angiograms, the following measures were taken ${ }^{16}$ : First, the $\mathrm{x}$-ray system was exactly positioned, as was noted at the time of the intervention. Second, all study frames to be analyzed were selected at end-diastole to minimize foreshortening. Third, the investigator-determined beginning and end point of a segment of a major coronary artery were identified according to the definitions of the American Heart Association. ${ }^{17}$ Finally, Polaroid photographs were taken of the video image with the detected contours superimposed to ensure that the analysis was performed on the same coronary segments in consecutive angiograms. Patients with balloon angioplasty were enrolled in ongoing restenosis trials, and therefore, according to the protocol, systematically received intracoronary nitroglycerin before and after angioplasty, and during follow-up catheterization, where-

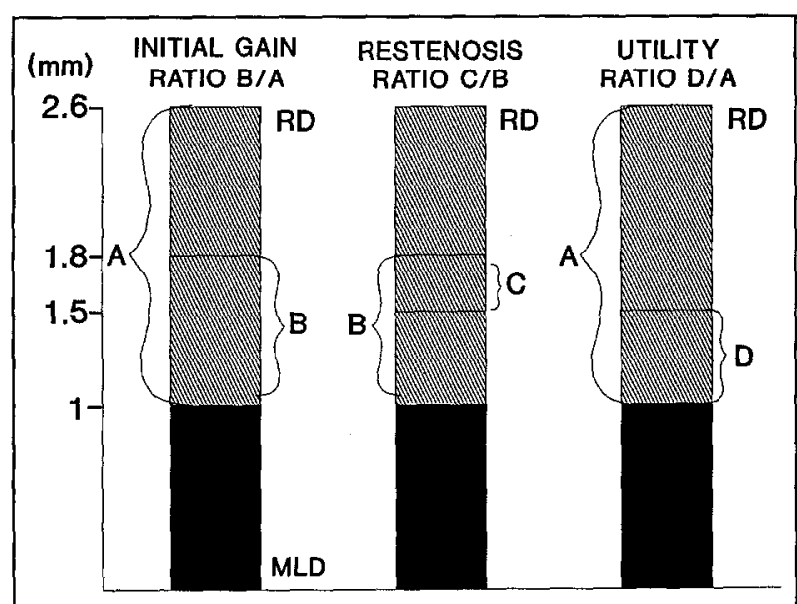

FIGURE 2. Graphic illustration of principle of initial gain, restenosis and utility indexes. Initial gain index is represented by the ratio $B / A$, restenosis index by $C / B$, and utifity index by D/A. A = maximal achievable increase in minimal huminal diameter (MLD); B = gain in MLD during procedure; C = reduction during follow-up; $D=$ long-term result; $R D=$ reference diameter. as patients with atherectomy were less frequently administered intracoronary nitroglycerin at recatheterization.

Restenosis: Two different criteria were used to define the restenosis rate. We have found a change in minimal lumen diameter $\geq 0.72 \mathrm{~mm}$ to be a reliable indicator of angiographic progression of vessel narrowing. 4,15,16 This value takes into account the limitations of coronary angiographic measurements and represents the long-term variability for repeat measurements of a coronary stenosis using CAAS. The second criterion for restenosis chosen was an increase in the diameter stenosis from $<50 \%$ after intervention to $\geq 50 \%$ at followup. This criterion was selected because clinical practice continues to assess lesion severity by percent stenosis.

Assessment of initial gain, restenosis and utility ratio: To compare the relative efficacy of various interventional techniques, it is critical to relate the procedural outcome and changes during follow-up to the maximal achievable result. Therefore we propose the use of the aforementioned ratios in the evaluation of intracoronary interventions. Briefly, quantitative angiographic changes after intracoronary intervention may be divided in 3 stages (Figure 2). The first or "operational stage," is characterized by the interaction of the operational device with the lesion. In becoming operational, the diameter of the device may expand (directional atherectomy, balloon, stent) or maintain its original dimensions (laser, transluminal extraction catheter, rotational ablation). During this stage, the maximal effect of the device is achieved and determines to what extent the minimal luminal diameter may be increased. The initial gain index represents the ratio between the achieved luminal and maximal achievable luminal improvements (reference diameter minus minimal lumen diameter (MLD) before intervention), and is described by the following equation: initial gain index: change in MLD at intervention/reference diameter - MLD before intervention. The initial gain index ranges from 0 (no effect) to 1 (no residual stenosis). The second stage or "restenosis stage" begins during follow-up when biological processes determine the extent of intimal hyperplasia ultimately leading to a loss of luminal gain.

The restenosis index represents the ratio of decrease in luminal diameter improvement during follow-up and the achievcd changes induced by intracoronary intervention, and is described by the following equation: restenosis index: MLD after intervention - MLD followup/change in MLD at intervention. The restenosis index ranges from 0 (initial benefit intact) to 1 (initial benefit completely lost).

The utility index represents the ratio of the net gain in lumen improvement at follow-up and the maximal achievable luminal improvement, and is described by the following equation: utility index: change in MLD at 
intervention - change in MLD at follow-up/reference diameter - MLD before intervention. The utility index ranges from 0 (no utility) to 1 (perfect result).

Matching process: The coronary artery tree was subdivided in 15 segments according to American Heart Association guidelines, ${ }^{18}$ and the lesions were individually matched according to stenosis location and reference diameter. The principles of matching are threefold: the angiographic dimensions of matched lesions are assumed to be "identical," the observed difference between the 2 "identical" lesions must be within the range of CAAS reproducibility of $0.1 \mathrm{~mm}$ ( 1 standard deviation), ${ }^{5}$ and finally, the reference diameters of the matched vessels are selected within a range of \pm $0.3 \mathrm{~mm}$ (3 standard deviations; $99 \%$ confidence limits). To assess the immediate result of atherectomy and balloon angioplasty, 30 coronary artery lesions were selected by an independent technician (EMvS) from a consecutive series of successfully dilated balloon angioplasty lesions while complying with the selection criteria of matching. At the time of selection, the investigators were unaware of the 6-month angiographic outcome of these lesions. Matching was considered adequate if the mean difference of the reference diameter between the groups equaled 0 with standard deviation $<0.3$ $\mathrm{mm} .{ }^{19}$ Currently, the Thoraxcenter angiographic database contains quantitatively assessed stenosis data for 2,300 patients treated with either angioplasty $(\mathrm{n}=$ $1847)$, intracoronary stenting $(n=406)$, or directional or rotational atherectomy $(\mathrm{n}=120)$.

Statistical analysis: All values are expressed as mean \pm 1 standard deviation. Comparisons of the severity of minimal luminal diameter, area plaque, diameter stenosis, curvature value symmetry index and length between the groups were performed using analysis of variance and the unpaired Student's $t$ test. Differences were considered statistically significant at $\mathrm{p}<0.05$.

\section{RESULTS}

Preprocedural stenosis characteristics of the matched patients are listed in Table I. Matching for stenosis location and reference diameter resulted in groups of patient with comparable severity of lesions. Matching was considered adequate because the reference diameter was equal in both groups ( $3.03 \pm 0.57$ vs $3.07 \pm 0.55 \mathrm{~mm} ; \mathrm{p}=$ not significant), whereas the mean difference for this parameter between the groups was $0.0 \mathrm{~mm}$ (standard deviation $0.2 \mathrm{~mm}$ ). Preprocedural minimal luminal diameter in the groups with atherectomy and angioplasty were $1.08 \pm 0.37$ and $1.15 \pm$ $0.36 \mathrm{~mm}$, respectively. The other stenosis parameters (diameter stenosis, area plaque, symmetry index and length) did not differ significantly, with the sole exception of curvature value, which was lower in the group
TABLE I Matched Preprocedural Stenosis Characteristics of 30 Patients with Successful Coronary Atherectomy Compared with Successful Balloon Angioplasty

\begin{tabular}{|lcc|}
\hline & $\begin{array}{l}\text { Before } \\
\text { Atherectomy }\end{array}$ & $\begin{array}{l}\text { Before } \\
\text { Angioplasty }\end{array}$ \\
\hline Reference diameter $(\mathrm{mm})$ & $3.03 \pm 0.57$ & $3.07 \pm 0.55$ \\
Minimal luminal diameter & $1.08 \pm 0.37$ & $1.15 \pm 0.36$ \\
$\quad(\mathrm{~mm})$ & $64 \pm 10$ & $63 \pm 8$ \\
Diameter stenosis $(\%)$ & $9.5 \pm 6.4$ & $8.4 \pm 3.6$ \\
Area plaque (mm $\left.{ }^{2}\right)$ & $15.9 \pm 7.0$ & $22.2 \pm 13.1^{*}$ \\
Curvature value & $0.6 \pm 0.2$ & $0.5 \pm 0.3$ \\
Symmetry index & $6.8 \pm 2.7$ & $6.5 \pm 2.6$ \\
Length & & \\
\hline${ }^{*} \mathrm{p}<0.02$. & \\
\hline
\end{tabular}

TABLE II Quantitative Comparison of the Immediate and Long-Term Results of Atherectomy and Balloon Angioplasty $(n=30)$

\begin{tabular}{|llll|}
\hline & Atherectomy & Angioplasty & \multicolumn{1}{l}{$\begin{array}{l}\text { Unpaired } \\
t \text { Test }\end{array}$} \\
\hline $\begin{array}{l}\text { Reference diameter } \\
\text { (mm) }\end{array}$ & & & \\
Pre & $3.03 \pm 0.57$ & $3.07 \pm 0.55$ & NS \\
Post & $3.24 \pm 0.32$ & $3.09 \pm 0.56$ & NS \\
Follow-up & $2.81 \pm 0.57$ & $3.04 \pm 0.65$ & NS \\
Minimal luminal & & & \\
$\quad$ diameter (mm) & & & \\
Pre & $1.08 \pm 0.37$ & $1.15 \pm 0.36$ & NS \\
Post & $2.61 \pm 0.33$ & $1.92 \pm 0.31$ & 0.0000 \\
Follow-up & $1.69 \pm 0.58$ & $1.57 \pm 0.58$ & NS \\
Difference in minimal & & & \\
$\quad$ luminal diameter (mm) & & \\
Post to pre & $1.53 \pm 0.47$ & $0.77 \pm 0.30$ & 0.0000 \\
Post to follow-up & $0.92 \pm 0.69$ & $0.35 \pm 0.51$ & 0.0005 \\
Diameter stenosis (\%) & & & \\
Pre & $64 \pm 10$ & $63 \pm 8$ & NS \\
Post & $19 \pm 9$ & $37 \pm 10$ & 0.0000 \\
Follow-up & $37 \pm 18$ & $47 \pm 18$ & 0.04 \\
Difference in diameter & & & \\
stenosis (\%) & & & \\
Pre-post & $45 \pm 12$ & $26 \pm 12$ & 0.0000 \\
Follow-up-post & $18 \pm 17$ & $10 \pm 17$ & NS \\
\hline NS = not significant; Post $=$ after intervention; Pre $=$ before intervention. \\
\hline
\end{tabular}

with atherectomy than in that with angioplasty (15.9 \pm 7.0 vs $22.2 \pm 13.1 ; p<0.02$ ).

The immediate efficacy of atherectomy and angioplasty as assessed by quantitative angiography is shown in Table II and Figure 3. As expected, both atherectomy and balloon angioplasty significantly improved minimal luminal diameter $(1.08 \pm 0.37$ to $2.61 \pm 0.33$ $\mathrm{mm}[\mathrm{p}<0.0001]$, and $1.15 \pm 0.36$ to $1.92 \pm 0.31 \mathrm{~mm}$ [p $<0.001$, respectively), but the increase in minimal luminal diameter was superior in the group with atherectomy than in that with angioplasty $(1.53 \mathrm{vs} 0.77 \mathrm{~mm}$; $\mathrm{p}<0.0001$ ). Accordingly, the initial gain ratio of atherectomy was also superior when compared with that of angioplasty $(0.84 \pm 0.36$ vs $0.41 \pm 0.18 ; p<0.00001)$. Thus, percent diameter stenosis was reduced from $64 \pm$ 10 to $19 \pm 9 \%(p<0.0001)$ in the group with atherec- 
TABLE III Quantitative Assessment of Initial Gain, Restenosis and Utility Ratios After Atherectomy and Balloon Angioplasty $(n=30)$

\begin{tabular}{|llll|}
\hline & Atherectomy & Angioplasty & $\begin{array}{l}\text { Unpaired } \\
t \text { Test }\end{array}$ \\
\hline Initial gain ratio & $0.84 \pm 0.36$ & $0.41 \pm 0.18$ & 0.0000 \\
Restenosis ratio & $0.56 \pm 0.55$ & $0.62 \pm 1.10$ & NS \\
Utility ratio & $0.29 \pm 0.33$ & $0.23 \pm 0.28$ & NS \\
\hline NS = not significant. & & & \\
\hline
\end{tabular}

tomy, and from $63 \pm 8$ to $37 \pm 10 \%(\mathrm{p}<0.001)$ in the that with angioplasty.

At follow-up, all patients with atherectomy and angioplasty included in this study underwent 6-month control catheterization. Angiographic follow-up in the groups with atherectomy and angioplasty were 95 and
$92 \%$, respectively. Angiographic analysis at follow-up (Table II and Figure 4) showed a decrease in minimal luminal diameter in both groups $(2.61 \pm 0.33$ to 1.69 $\pm 0.58 \mathrm{~mm}$ with atherectomy, $1.92 \pm 0.31$ to $1.57 \pm$ $0.58 \mathrm{~mm}$ with angioplasty). Thus, the loss in minimal luminal diameter was more pronounced in the group with atherectomy than in that with angioplasty $(0.92 \pm$ 0.69 vs $0.35 \pm 0.51 \mathrm{~mm} ; \mathrm{p}<0.0005$ ). Accordingly, percent diameter stenosis increased from $19 \pm 9$ to 37 $\pm 18 \%$ in the group with atherectomy, and from $37 \pm$ 10 to $47 \pm 18 \%$ in that with angioplasty. The concomitant restenosis and utility ratios are listed in Table III. Percent restenosis (detectable hyperplasia by quantitative coronary analysis) according to the $0.72 \mathrm{~mm}$ decrease in minimal luminal diameter (2 times the standard deviation of the long-term variability of the mini-
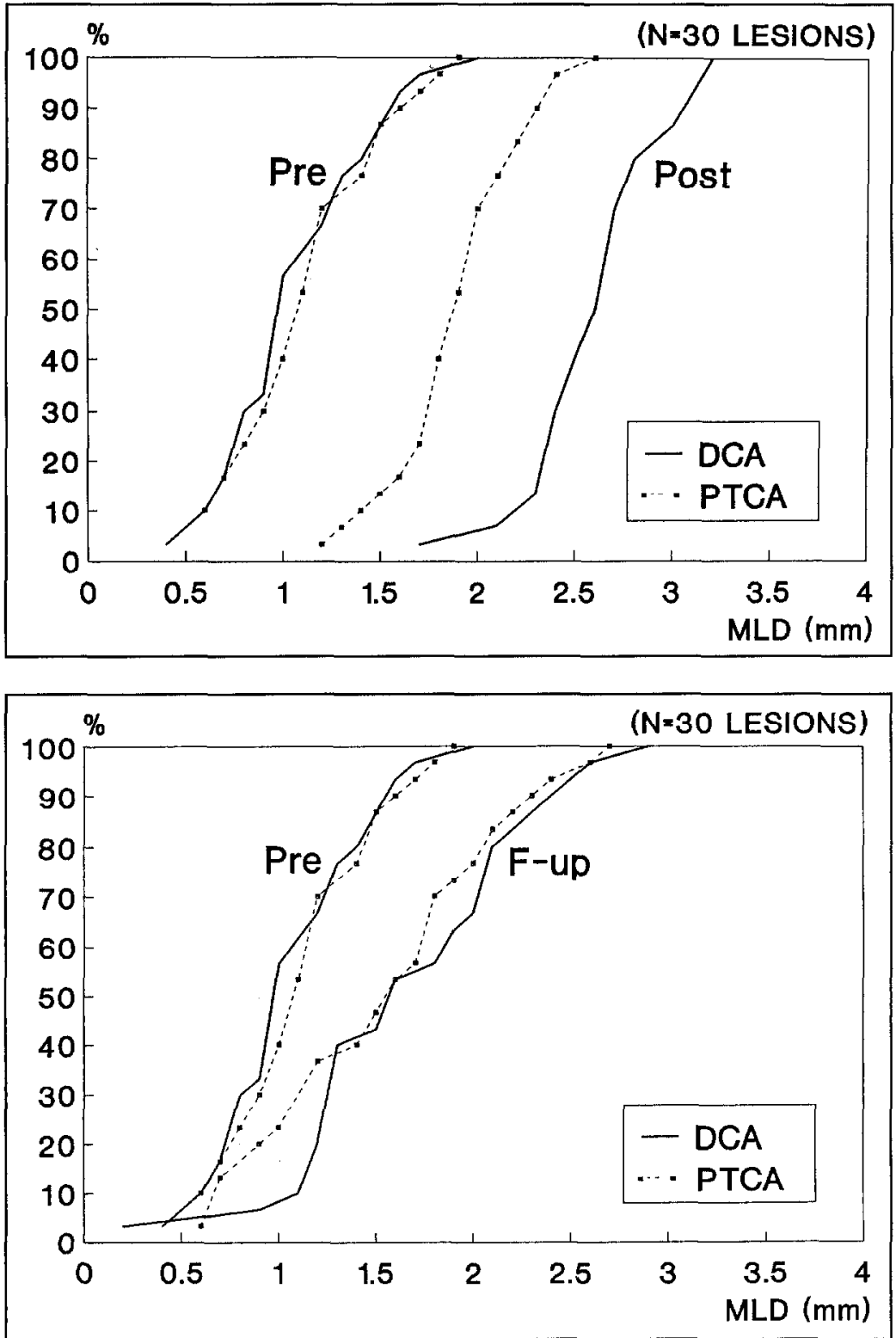

FICURE 3. Cumulative frequency of immediate results of directional atherectomy (DCA) and balloon angioplasty (PTCA) in 30 matched lesions. Directional atherectomy resulted in an increase in minimal hlminal diameter (MLD) from 1.08 to 2.61 $\mathrm{mm}$, whereas angioplasty induced an increase from 1.15 to $1.92 \mathrm{~mm}$. Post = after intervention; Pre $=$ before intervention.
FICURE 4. Cumulative frequency of longterm results of directional atherectomy and angioplasty in this matched population. At 6-month follow-up (F-up), initial favorable result of atherectomy is lost compared with that of balloon angioplasty. Other abbreviations as in Figure 3 . 
mal luminal diameter measurements using CAAS criterion) was $60 \%$ in the group with atherectomy versus $36 \%$ in that with angioplasty. When restenosis is defined by an increase in diameter stenosis $\geq 50 \%$ at follow-up, the restenosis percentages are 20 vs $16 \%$ (atherectomy vs angioplasty).

\section{DISCUSSION}

Coronary angioplasty is now an accepted form of treatment for patients with coronary artery disease. In the past, exponential growth in angioplasty has partly been the result of an increase patients returning with restenosis. Despite extensive efforts to improve catheter equipment we are still unable to effectively reduce the rate of restenosis. Because no fundamental design changes in balloon or balloon-derived catheter techniques are emerging, debulking techniques, such as directional atherectomy, have been introduced to improve the angioplastic process and to presumably reducc the rate of restenosis. The potential advantages of debulking atheromatous tissue over remodeling plaque with balloon angioplasty include: minimizing smooth muscle cell injury by wall stress; eliminating smooth muscle cells and thereby reducing their proliferative potential; improving regional blood flow and rheology by inducing fewer fissures or dissections; reducing radial stretch forces, as applied with a dilating balloon; and creating larger increases in minimal luminal diameter. Indeed, recent studies have reported a larger increment in luminal improvement after atherectomy than after conventional balloon angioplasty, ${ }^{14}$ whereas other investigators observed a low incidence of postprocedural dissections. ${ }^{11,12,14}$

Study design: Whether atherectomy is superior to balloon angioplasty can only be assessed by a randomized study. This type of study would take several years, during which continuing refinements and improvements of catheter systems would take place, rendering the comparison unreliable and open to criticism. Therefore, we proposed a matching technique based on stenosis location and reference diameter to compare the results of various intracoronary interventional techniques. At present, this technique may be the best surrogate for a randomized trial when one tries to compare the shortand long-term results of atherectomy with those of conventional angioplasty. Using our matching program we selected comparable stenotic lesions with respect to baseline characteristics (minimal luminal diametcr, diameter stenosis, length, area plaque and symmetry index) as assessed by quantitative angiography. This study group reflects the baseline stenosis characteristics in patients treated with atherectomy ${ }^{20}$ or balloon angioplasty. 4,21
Immediate results: This study confirms previous reports of improved luminal gain after atherectomy compared with that after conventional angioplasty. ${ }^{14}$ Atherectomy resulted in a twofold increase in minimal luminal diameter $(1.09 \pm 0.37$ to $2.61 \pm 0.33 \mathrm{~mm})$ compared with that with angioplasty $(1.15 \pm 0.36$ to $1.92 \pm 0.31 \mathrm{~mm})$. Accordingly, percent diameter stenosis decreased more dramatically after atherectomy than after angioplasty. This improvement in luminal gain with atherectomy may be due to 3 mechanisms. First, introduction of the bulky device itself causes a lumen enlargement due to the "Dotter" effect. Second, the subsequent inflation of the support balloon may lead to further enlargement by stretching of the vessel wall. Finally, excision of the plaque determines the final result.

Restenosis: Recurrence of a stenusis after intracoronary intervention may be assessed by clinical symptoms, stress testing or coronary angiography. Because symptoms and functional achievement at exercise testing have low predictive values in regard to rcstcnosis, diagnosis of restenosis should be based on reproducible quantitative angiographic measurements using a computer-assisted technique with either automated edge detection or videodensitometry. Furthermore, the definition of restenosis is a matter of ongoing debate. It has been shown by our investigative group,, 22 as well as by others, ${ }^{3}$ that the determination of the severity of stenosis using percent diameter stenosis does not reflect changes after angioplasty, because the adjacent part of the dilated vessel may also be involved in the restenosis process, or the reference diameter may be simultaneously reduced. Therefore, we selected minimal luminal diameter as a parameter for the morphologic changes after atherectomy or angioplasty. Minimal luminal diameter at follow-up was $1.69 \mathrm{~mm}$ for the group with atherectomy compared with $1.57 \mathrm{~mm}$ for that with balloon angioplasty $(p=$ not significant). These findings are similar to previously documented late follow-up studies of coronary balloon angioplasty (1.69 to $1.82 \mathrm{~mm})^{4}$ and stenting $(1.68 \mathrm{~mm}){ }^{23}$ Using the $\geq 50 \%$ diameter stenosis criterion, the rates of restenosis after atherectomy and angioplasty were 20 and $16 \%$, respectively. Previous studies on restenosis after primary coronary atherectomy reported an incidence of restenosis of $20 \% 11,12$ using the $\geq 50 \%$ criterion. Thus, during follow-up, the initial greater gain in luminal diameter after atherectomy compared with that after balloon angioplasty is totally lost. At follow-up, the reduction in minimal luminal diameter was $0.92 \mathrm{~mm}$ aftcr atherectomy compared with $0.35 \mathrm{~mm}$ after angioplasty $(\mathrm{p}=$ 0.0005 ). Although minimal luminal diameter changed more dramatically in the group with atherectomy than 
in that with angioplasty, both had equal restenosis $(0.56$ vs $0.62 ; p=$ not significant $)$ and utility $(0.29$ vs $0.23 ; \mathrm{p}=$ not significant) ratios, indicating that the relative changes are equal for both interventional techniques.

Animal and atherectomy studies ${ }^{11-13,20}$ have demonstrated that fibrointimal hyperplasia may develop in coronary arteries previously treated by balloon angioplasty or atherectomy. Pathologic findings have raised a theory that deeper vascular injury is associated with a greater intimal proliferation. Injury beyond the subintimal level has been shown to be associated with more extensive intimal proliferation. ${ }^{24}$ These data are supported by Webster et $\mathrm{a}^{25}$ who found a greater smooth muscle proliferation after high-inflation pressure with the same balloon size when compared with that after low pressure. Furthermore, an initial follow-up study after atherectomy indicates that this process may be accelerated when deep vessel wall components such as media and adventitia are removed. ${ }^{13}$ Additionally, atherectomy may lead to profound disrupture of the vessel wall architecture. ${ }^{26}$ Finally, the introduction of the bulkier atherectomy device may potentially lead to a greater amount of vessel wall stretching compared with that with the smaller balloon catheter system. All these influences may account for the greater cellular proliferation of the lesion treated by atherectomy.

Study limitations: There are several limitations to this study. First, it is an uncontrolled, observational study limited to a subset of patients with successful coronary atherectomy or balloon angioplasty. This consecutive series of patients were studied by investigators unaware of the late angiographic results. Although matching for angiographic variables is a promising technique to assess the efficacy of intracoronary interventions, patient- and procedure-related variables are not included in the analysis. Second, lesion complexity was not incorporated in the analysis. This is usually defined qualitatively ${ }^{27}$; however, an objective and quantitative description of stenosis morphology has recently been introduced. ${ }^{28}$ Further improvement in quantitative analysis may assess lesion morphology in a continuous scale fashion rather than assigning lesions to discrete categories. This type of analysis should be incorporated in future trials studying the efficacy of various interventional techniques. Third, this study is bascd on early experiences with atherectomy. Careful patient selection, futurc design changes and improved operator experience may further improve the immediate and long-term results. Thus, controlled clinical trials are needed in the future to determine the immediate angiographic results and long-term efficacy of these interventions, as well as the benefit, if any, to particular subgroups of patients.
These studies should also address the presumed time frame for restenosis after any particular intervention.

Acknowledgment: We acknowledge Jan Tijssen, $\mathrm{PhD}$, for statistical assistance. We thank Jaap Pameyer and the Cardialysis corelab for analyzing the coronary angiograms.

\section{REFERENCES}

1. Holmes DR, Vlietstra RE, Smith HC. Restenosis after angioplasty: a report from the angioplasty registry from the NHLBI. Am J Cardiol 1984;53:77C-81C 2. Leimgruber PP, Roubin GS, Hollman J, Cotsonis GA, Meier B, Douglas JC King SB, Grüntzig AR. Restenosis after successful angioplasty in patients with single vessel disease. Circulation 1986;73:710-717.

3. Nobuyoshi M, Kimura T, Nosaka H. Restenosis after successful percutaneous transluminal coronary angioplasty: serial angiographic follow-up in 229 patients. $J$ Am Coll Cardiol 1988;12:616-623.

4. Serruys PW, Luyten HE, Beatt KJ, Geuskens R, de Feyter PJ, van den Brand M, Reiber JHC, ten Kate IIJ, van Es GA, I Iugenholtz PG. Incidencc of restcnosis after successful coronary angioplasty: a time related phenomenon. Circulation 1988;77:361-371.

5. Reiber JHC, Serruys PW. Quantitative coronary angiography. In: Marcus ML, Schelbert HR, Skorton DJ, Wolf GL, eds. Cardiac Imaging: A Comparison to Braunwald's Heart Disease. Philadelphia: W.B. Saunders, 1991:213-280.

6. Johnson DE, Hinohara T, Seimon MK, Braden L, Simpson JB. Primary peripheral arterial stenosis and restenosis excised by transluminal atherectomy: a histopathologic study. J Am Coll Cardiol 1990;15:419-425.

7. Essed CE, van den Brand M, Becker AE. Transluminal coronary angioplasty and early restenosis. Br Heart $J$ 1983;49:393-396.

8. Austin GE, Ratliff NB, Hollman J, Tabei S, Phillips DF. Intimal proliferation of smooth muscle cells as an explanation for recurrent coronary artery stenosis after percutaneous transiuminal coronary angioplasty. $J$ Am Coll Cardiol 1985;6:369-375.

9. Giraldo AA, Esposo OM, Meiss JM. Intimal hyperplasia as a cause of restenosis after percutaneous transluminal coronary angioplasty. Arch Pathol Lab Med 1985;109:173-175.

10. Liu MW, Roubin GS, King SB. Restenosis after coronary angioplasty: potential biological determinants and role of intimal hyperplasia. Circulation 1989;79:1374 1387

11. Safian RD, Gelbfish JS, Erny RE, Schnitt SJ, Schmidt D, Baim DS. Coronary atherectomy: clinical, angiographic and histologic findings and observations regarding potential mechanisms. Circulation 1990;82:69-79.

12. Robertson GC, Hinohara T, Selmon MR, Johnson DE, Simpson JB. Directional coronary atherectomy. In: Topol EJ, ed. Textbook of Interventional Cardiology. W.B. Saunders: Philadelphia, 1990:563-579.

13. Garratt KN, Holmes DR, Bell MR, Bresnahan JF, Kaufmann UP, Vlietstra RE, Edwards WD. Restenosis after directional coronary atherectomy: differences between primary atheromatous and restenosis lesions and influence of subintimal tissue resection. J Am Coll Cardiol 1990;16:1665-1671.

14. Muller DWM, Ellis SG, Debowey DL, Topol EJ. Quantitative angiographic comparison of the immediate success of coronary angioplasty, coronary atherectomy and endoluminal stenting. Am J Cardiol 1990;66:938-942.

15. Umans VA, Strauss BH, de Feyter PJ, Serruys PW. Edge detection versus videodensitometry for quantitative angiographic assessment of directional coronary atherectomy. Am J Cardiol 1991:68;534-539.

16. Reiber JHC, Serruys PW, Kooyman CJ, Wijns W, Slager CJ, Gerbrands JJ, Schuurbiers JCH, den Boer A, Hugenholtz PG. Assessment of short-, mediumand long-term variations in arterial dimensions from computer-assisted quantitation of coronary cineangiograms. Circulation 1985:71:280-288.

17. Serruys PW, Strauss BH, van Beusekom HM, van der Giessen. Stenting of coronary arteries: has a modern Pandorra's box been opened? $J$ Am Coll Cardiol 1991;17:143B-154B.

18. Austen WG, Edwaerds JF, Frye RL, Gensini GG, Gott VL, Griffith LSC McGoon DC, Murphy ML, Roe BB. A reporting system in patients evaluated for grading of coronary artery disease. Report of the ad-hoc committee for grading coronary artery disease, council on cardiovascular surgery. American Heart Association. Circulation 1975;51:7-13.

19. Bland JM, Altman DG. Statistical methods for assessing agreement between two methods of clinical measurement. Lancet 1986;i:307-310. 
20. Serruys PW, Umans VA, Strauss BH, van Suylen RJ, van den Brand M, Suryapranata $\mathrm{H}$, de Feyter PJ. Quantitative angiography after directional coronary athcrcctomy. Br Heart $J$ 1991;66:122-129.

21. Serruys PW, Rutsch W, Heyndrickx GR, Danchin N, Mast G, Wijns W, Rensing BJ, Vos J, Stibbe J. Prevention of restenosis after percutaneous transiuminal coronary angioplasty with thromboxane $\mathrm{A} 2$ receptor blockade, a randomized, double-blind aspirin-placebo controlled trial. Circulation: in press.

22. Beatt KJ, Luyten HE, de Feyter PJ, van den Brand M, Reiber JHC, Serruys $P W$. Changes in diameter of coronary artery segments adjacent to stenosis after percutaneous transluminal balloon angioplasty: failure of percent diameter stenosis measurement to reflect morphologic changes induced by balloon dilation. $J \mathrm{Am}$ Coll Cardiol 1988;12:315-323.

23. Serruys PW, Strauss BH, Beatt KJ, Bertrand ME, Puel J, Rickards AF, Meier B, Goy JJ, Vogt P, Kappenberger L, Sigward U. Angiographic follow-up after placement of a self-expanding coronary artery stent. $N$ Engl $J$ Med 1991;1:28-34.
24. Nobuyoshi M, Kimura T, Ohishi $H$, Horiushi $H$, Nosaka $H$, Hamasaki $N$, Yokoi H, Kim K. Restenosis after percutaneous transluminal coronary angioplasty. pathologic observatiors in 20 patients. $J$ Am Coll Cardiol 1991;17: 433-439.

25. Webster MWI, Chesebro JH, Heras M, Mruk JS, Grill DE, Fuster V. Effect of balloon inflation on smooth muscle cell proliferation in the porcine carotid artery (abstr). J Am Coll Cardiol 1990;15:165A.

26, van Suylen RJ, Serruys PW, Simpson JB, de Feyter PJ, Strauss BH, Zondervan PE. Delayed rupture of right coronary artery after directional atherectomy for bail-out. Am Heart $J$ 1991;121:914-916.

27. Ambrose JA, Winters SL, Stern A, Eng A, Teichholtz LE, Gorlin R, Fuster V. Angiographic morphology and the pathogenesis of unstable angina pectoris. $J$ Am Coll Cardiol 1985;5:609-616.

28. Kalbfleish SJ, McGillem MJ, Simon SB, DeBoe SF, Pinto IMF, Mancin GBJ. Automated quantitation of indexes of coronary lesion complexity. Circulation 1990;82:439-447. 